\title{
UNCERTAINTY IN STATIC PRESSURE CORRECTION IN A SUBSONIC WIND TUNNEL
}

\author{
M. L. C. C. Reis, O. A. F. Mello, \\ and M. Chisaki, \\ ABSTRACT
The static pressure p on the subsonic Wind Tunnel of the Aerodynamic Testing Laboratory
of the Institute of Aeronautics and Space - IAE, Aerospace Technical Center - CTA, is
measured using an absolute pressure sensor, located on the upper test section wall. This
measurement is not taken at the same location as the one where the model is mounted
during the actual wind tunnel test. This fact raises the need for a correction during data
reduction. The identification and evaluation of the associated error source is important
because the static pressure is an input quantity for the calculation of the total pressure $p_{\text {t }}$,
Mach number M and density $\rho$ during the test. The present paper is concerned with the
determination of the relationship between the static pressure measured on the tunnel's
upper wall and that at the model location, and with the analysis of the uncertainty
propagation for the measured flow parameters.
Keywords: subsonic wind tunnel, Aerodynamic Testing \\ ABSTRACT
The static pressure p on the subsonic Wind Tunnel of the Aerodynamic Testing Laboratory
of the Institute of Aeronautics and Space - IAE, Aerospace Technical Center - CTA, is
measured using an absolute pressure sensor, located on the upper test section wall. This
measurement is not taken at the same location as the one where the model is mounted
during the actual wind tunnel test. This fact raises the need for a correction during data
reduction. The identification and evaluation of the associated error source is important
because the static pressure is an input quantity for the calculation of the total pressure $p_{\text {t }}$,
Mach number M and density $\rho$ during the test. The present paper is concerned with the
determination of the relationship between the static pressure measured on the tunnel's
upper wall and that at the model location, and with the analysis of the uncertainty
propagation for the measured flow parameters.
Keywords: subsonic wind tunnel, Aerodynamic Testing \\ ABSTRACT
The static pressure p on the subsonic Wind Tunnel of the Aerodynamic Testing Laboratory
of the Institute of Aeronautics and Space - IAE, Aerospace Technical Center - CTA, is
measured using an absolute pressure sensor, located on the upper test section wall. This
measurement is not taken at the same location as the one where the model is mounted
during the actual wind tunnel test. This fact raises the need for a correction during data
reduction. The identification and evaluation of the associated error source is important
because the static pressure is an input quantity for the calculation of the total pressure $p_{\text {t }}$,
Mach number M and density $\rho$ during the test. The present paper is concerned with the
determination of the relationship between the static pressure measured on the tunnel's
upper wall and that at the model location, and with the analysis of the uncertainty
propagation for the measured flow parameters.
Keywords: subsonic wind tunnel, Aerodynamic Testing \\ Aerospace Technical Center \\ Institute of Aeronautics and Space \\ Praça Mal. Eduardo Gomes, $n^{\circ} 50$ \\ São José dos Campos, São Paulo \\ 12228-904 \\ mluisareis@yahoo.com.br
}

\section{INTRODUCTION}

Wind tunnel tests are fundamental for the development and bettering of aerodynamic projects. Information provided by wind tunnel helps calculate aerodynamic loads due to the wind and provides support in decision making related to improvement and optimization of the project. There are a wide variety of wind tunnels of different configurations, dimension and power around the world, with the aim of performing several different types of aerodynamic measurements: load, pressure, tracking, visualization, etc, tested on different types of models and for a great range of flow velocity.

The TA-2 wind tunnel of the Aerodynamic Test Laboratory ASA-L, of the Institute of Aeronautic and Space, IAE, of the Aerospace Technical Center, CTA, is a subsonic closed-circuittype tunnel, with typical maximum velocity and power of $140 \mathrm{~m} / \mathrm{s}$ and $1.18 \mathrm{MW}$, respectively. The test section has a rectangular geometric shape and an area of $6.30 \mathrm{~m}^{2}$. The principal customers of TA2 are the Brazilian Air Force, the aeronautical, naval and construction industries, science and technology institutes and universities. The models tested include aircrafts, space vehicles, submarines, oil rigs, flyovers, masts and buildings.

The general aim of the study conducted in this paper is to contribute to the guarantee of the metrological reliability of the tests performed in the TA-2 wind tunnel. More specifically, the measurement and analysis of flow irregularities identify error sources that can be quantified and taken into account in the assessment of uncertainty.

A survey of error sources of tests carried out in the TA-2 and the description of the systematized methodology for the evaluation of the uncertainties of the aerodynamic test parameters are presented in Reis (2000) and in Reis et alii (2000). A retrospective and prospective analysis related to the assessment, control and optimization of wind tunnel flow quality can be found in Owen (2000).

\section{Pressure measurement}

In the aerodynamic test technology, there are three definitions of pressure for flowing fluids (Benedict, 1977), since a directed kinect energy of flow is superposed on the random kinetic energy of the fluid molecules. The terminology applied is:

- static pressure $p$ : is the actual pressure of the gas, whether in motion or at rest. Static pressure at a given point is the pressure a sensor would measure if it were moving along with the flow at that point; it is the ramification of gas molecules moving about with random motion and transferring their momentum to or across surfaces (Andrerson, 1984);

- dynamic pressure $q$ : is the pressure equivalent to the direct kinetic energy of the flow; and - total pressure $p_{t}$ : the sum of the static and dynamic pressures. Total pressure at a giving point in a flow is that pressure that would exist if the flow were slowed down isentropically (adiabatic and 


\section{TECNOLOGIA/TECHNOLOGY}

reversible process) to zero velocity. For the case of a gas that is not moving, the total and static pressures are synonymous.

The instrument which measures the total pressure at a point in the flow is the Pitot tube. A total pressure measurement and static pressure measurement can be combined in the instrument, which results in the so-called Pitot-static probe (Fig. 1).

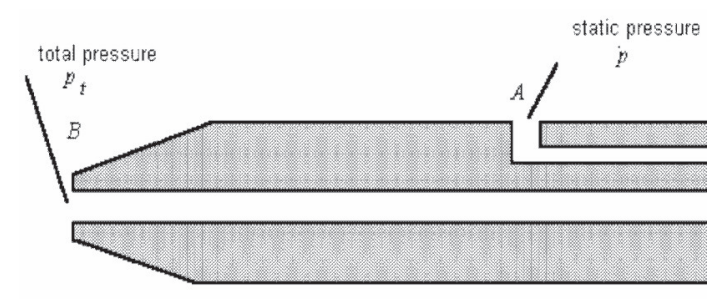

Figure 1. Diagram of a Pitot-static probe. Small holes in the surface (A) provide the static pressure $p$. The total pressure $p_{t}$ is provided at point $\mathrm{B}$.

\section{The correction of static pressure}

The static pressure measurement at TA-2 is carried out by a Pitot-static probe attached to a gage probe. The Pitot tube is manufactured by "Airflow Developments Limited". A "Statham" differential pressure gage, range $2.5 \mathrm{psi}$ (17236.89323 $P a)$, serial number 16900 , model PMT6TC, is used to measure the dynamic pressure q. A "Paroscientific" absolute pressure probe, range 11.5 to $16.0 \mathrm{psia}$ (79289.70887 to $110316.1167 \mathrm{~Pa}$ ), resolution 0.1 psia $(689.4757 \mathrm{~Pa}$ ), model 216B101 , serial number 67001 is connected to the arrangement, as shown on the left side of Fig. (2), to measure the static pressure $p$. The total pressure $p_{t}$, is calculated through the sum of $q$ and $p$.

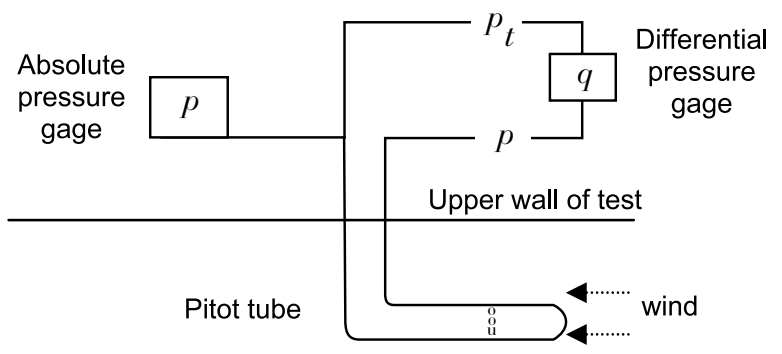

Figure 2. Pressure take. A differential gage provides the dynamic pressure $q$. An absolute pressure probe supplies the static pressure $p$.

The static and dynamic pressure measurements are not carried out at the position where the model will be tested, which raises the need for a correction. To assess this correction, two arrangements similar to the one specified in Fig. (2) are placed in the test section of the TA-2 wind tunnel. One of them is placed on the upper wall of the test section (position 1) and the other one is placed at the position where the model will be fixed during the test (position 2), as shown in Fig. (3). Another differencial gage, to measure the difference between the static pressures $\left(\Delta p=p_{1}-\right.$ $\left.p_{2}\right)$ at the two locations, is added.

\section{FUNCTIONAL RELATIONSHIP}

In this paper air flows will be analized as ideal gases. The basic physical quantities of a flowing gas are: temperature $T$, pressure $p$, density $\rho$ and velocity $V$. A knowledge of $T, p, \rho$ e $V$ at each point of a flow fully defines the flow field (Anderson, 1984).

The low-speed subsonic flow will be assumed to be incompressible and frictionless (inviscid).

\section{Flow field}

The quantities static pressure $p$, dynamic pressure $q$, total pressure $p_{t}$, density $\rho$, temperature $T$ and velocity $V$ of the flow, are related to each other by means of Bernoulli's equation and the equation of state for a perfect gas. (Anderson, 1984). The expressions for total pressure, density, velocity and Mach number of the flow are, respectively:

$$
\begin{aligned}
& p_{t}=p+q \\
& \rho=\frac{p}{R T} \\
& V=\sqrt{\frac{2 q}{\rho}}
\end{aligned}
$$

where $R$ is the specific gas constant.

By definition, the mach number $M$ at a point is the ratio between velocity $V$ and the speed of sound $a$ :

$$
M=\frac{V}{a}
$$

where $a$ is expressed by:

$$
a=\sqrt{\gamma R T}
$$




\section{TECNOLOGIA/TECHNOLOGY}

and the ratio of specific heats $\gamma$ is equal to 1.4 .

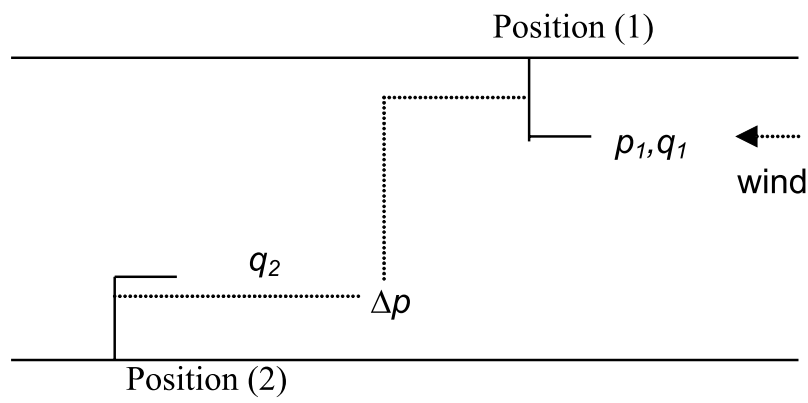

Figure 3. Correction of static pressure in the TA-2 test section.

\section{The law of propagation of uncertainty}

A complete statement of the result of a measurement should include a declaration of uncertainty (INMETRO, 1995). Therefore, the value of a measurand $Y$ should be expressed as (BIPM, 1995):

$$
Y=\bar{Y}+U
$$

When the measurand $Y$ is not measured directly, i.e., if it is determined from other input quantities $\left(X_{l}, X_{2}, \ldots, X_{N}\right)$, where $N$ is the number of input quantities, one should identify the functional relationship:

$$
Y=f\left(X_{1}, X_{2}, \ldots, X_{n}\right)
$$

The standard uncertainty of $y$, where $y$ is the estimate of the measurand $Y$, is obtained by combining the standard uncertainties of the input estimates $x_{1}, x_{2}, \ldots, x_{N}$. The combined standard uncertainty, denoted by $u_{c}(y)$, is the positive square root of the combined variance $u_{c}{ }_{c}(y)$, which is given by Eq. (8) below, i. e., it is an estimated standard deviation and characterizes the dispersion of the values which could reasonably be attributed to the measurand $Y$ :

$$
u_{c}^{2}=\sum_{i=1}^{N}\left(\frac{\partial f}{\partial x_{i}}\right)^{2} u^{2}\left(x_{i}\right)
$$

where $u(x)$ represents all the uncertainties derived from the measurement of $x_{i}$. This expression is valid for uncorrelated input quantities.

\section{Uncertainty of the flow quantities}

The expression of the combined standard
M. L. C. C. Reis et al. Uncertainty in Static Pressure...

uncertainty, calculated from Eq. (8), for the total pressure, density, velocity and Mach number are, respectively:

$$
u_{p t}^{2}=u_{p}^{2}+u_{q}^{2}
$$

$u_{\rho}^{2}=\left(\frac{1}{R T}\right)^{2} u_{p}^{2}+\left(\frac{-p}{R^{2} T}\right)^{2} u_{R}^{2}+\left(\frac{-p}{R T^{2}}\right)^{2} u_{T}^{2}$

or as relative combined uncertainty:

$$
\begin{aligned}
& \frac{u_{\rho}^{2}}{\rho}=\left(\frac{1}{p}\right)^{2} u_{p}^{2}+\left(\frac{-1}{R}\right)^{2} u_{R}^{2}+\left(\frac{-1}{T}\right)^{2} u_{T}^{2} \\
& u_{V}^{2}=\left(\frac{\sqrt{2}}{2} q^{-1 / 2} \rho^{-1 / 2}\right)^{2} u_{q}^{2}+\left(\frac{\sqrt{2}}{2} q^{1 / 2} \rho^{-3 / 2}\right)^{2} u_{\rho}^{2} \\
& u_{M}^{2}=\left(\frac{1}{a}\right)^{2} u_{V}^{2}+\left(\frac{-V}{a^{2}}\right)^{2} u_{a}^{2}
\end{aligned}
$$

for an uncertainty of the speed of sound in air given as:

$$
u_{a}^{2}=\left(\frac{\gamma R}{2 a}\right)^{2} u_{T}^{2}
$$

Uncertainties in $\gamma$ and $R$ negligible.

\section{RESULTS AND DISCUSSION}

With the wind tunnel operating, simultaneous measurements for the static pressure, $p_{1}$, and the dynamic pressure, $q_{1}$, at position (1), are taken, and the dynamic pressure $q_{2}$ at position (2) and the difference between the static pressures at the positions (1) and (2), $\Delta p$, are measured, for values of ascending and descending velocities.

Table (1) shows the values of the readings. The temperature $T$ is also measured at position (1) by a "Temptram" platinum sensor, model AS5250TT246N75A2N2, in order to calculate the flow density.

\section{Corrected static pressure}

The values of the difference of the static pressure $\Delta p$ between the positions (1) and (2) and of the dynamic pressure $q_{1}$ at position (1) are related through a least squares regression:

$$
\Delta p=-1.881-0.024 q_{1}
$$

with regression standard deviation $S_{\Delta p}$ equal to 2.334 Pa. 


\section{TECNOLOGIA/TECHNOLOGY}

The corrected static pressure $p_{c o r}$, is equal to the static pressure $p_{1}$ read at position (1) during the test, plus a correction that corresponds to the difference of static pressure $\Delta p$ obtained from the regression expressed by Eq. (15):

$$
p_{c o r}=p_{1}+\Delta p
$$

During the test, a dynamic pressure reading $q$, of $2941.995 \mathrm{~Pa}$, and a static pressure $p_{1}$ of 94762.503 $\mathrm{Pa}$ were observed. Therefore, through the use of Eq. (15) and (16), one gets the following correction for the static pressure at position (2): $p_{\text {cor }}=9467.759 \mathrm{~Pa}$, whose combined standard uncertainty is $1.9 \times 10^{-2} \mathrm{~Pa}$.

\section{Total pressure}

According to Eq. (1), the total pressure calculated from the corrected static pressure, is:

$p_{t}=9761.754 \mathrm{~Pa}$, with uncertainty equal to $1.9 \times 10^{-2} \mathrm{~Pa}$ according to Eq. (9). The predominance of the uncertainty component due to the static pressure measurement ( $u_{p}$ component of Eq. (9)), in relation to the uncertainty of dynamic pressure $u_{q}$, which corresponds to the calibration uncertainty of the sensor, can be seen.

Assuming the indication of the pressure gage placed on the upper wall of test section, we have the total pressure value $97704.498 \mathrm{~Pa}$, which differs by $0.1 \%$ from the value $97613.754 \mathrm{~Pa}$ taking into consideration the static pressure correction.

\section{Density}

In accordance with Eq. (2), the flow density,
M. L. C. C. Reis et al. Uncertainty in Static Pressure...

using the corrected static pressure, is:

$\rho=1.106 \mathrm{~kg} / \mathrm{m}^{3}$, with the combined standard uncertainty being $u_{p}=0.003 \mathrm{~kg} / \mathrm{m}^{3}$

Without the static pressure correction, the density value would be equal to $1.107 \mathrm{~kg} / \mathrm{m}^{3}$, a difference which is around $0.1 \%$.

\section{Flow velocity}

The flow velocity, according to Eq. (3), is: $\mathrm{V}=72.944 \mathrm{~m} / \mathrm{s}$

From Eq. (12), it can be seen that the uncertainty of the velocity corresponds to $0.13 \mathrm{~m} / \mathrm{s}$.

If the correction of static pressure is not used, the velocity value will be $72.909 \mathrm{~m} / \mathrm{s}$ which represents a variation of $0.05 \%$.

\section{Mach number}

The Mach number is calculated using Equations (4) and (5). For a temperature $T=300.22$ $K$, the speed of sound is:

$a=346.2016 \mathrm{~m} / \mathrm{s}$, for $R=285.157 \mathrm{Jg}^{-1} \mathrm{~K}^{-1}$

Therefore:

$M=0.2107$, with uncertainty 0.0008 .

For number of significant digits presented here, there is a difference of $0.05 \%$ between the corrected Mach number (0.2107) and the uncorrected one (0.2106).

Comparisons of the flow parameters for the corrected static pressure for greater flow velocity were carried out as well, which are shown in Table (2).

Table 1. Readings of dynamic and static pressure at position (1), $q_{1}$ and $p_{1}$, and for dynamic pressure $q_{2}$, at position (2). The temperature $T$ is measured at position (1). Units: milivolt.

\begin{tabular}{|c|c|c|c|c|c}
\hline Readings & $\mathrm{q}_{1}$ & $\mathrm{q}_{2}$ & $\Delta \mathrm{p}$ & $\mathrm{T}$ & $\mathrm{p}_{1}$ \\
\hline 1 & 0.08556 & 2.16896 & 2.82311 & 2.87167 & 5.40522 \\
\hline 2 & 2.66991 & 6.91583 & 2.73839 & 2.91000 & 5.34769 \\
\hline 3 & 5.32700 & 11.79317 & 2.65672 & 2.93945 & 5.28821 \\
\hline 4 & 7.84404 & 16.40438 & 2.59435 & 2.94470 & 5.23216 \\
\hline 5 & 10.52283 & 21.36641 & 2.51651 & 2.95218 & 5.17341 \\
\hline 6 & 13.05758 & 26.01773 & 2.43632 & 2.97764 & 5.11580 \\
\hline 7 & 15.65896 & 30.78167 & 2.36222 & 2.99625 & 5.05878 \\
\hline 8 & 18.32913 & 35.74431 & 2.28946 & 3.00417 & 4.99733 \\
\hline 9 & 15.77371 & 31.20034 & 2.33933 & 3.04986 & 5.05649 \\
\hline 10 & 13.18710 & 26.29075 & 2.43449 & 3.06595 & 5.11364 \\
\hline 11 & 10.48690 & 21.33562 & 2.51027 & 3.06498 & 5.17493 \\
\hline 12 & 7.97302 & 16.70877 & 2.59347 & 3.05860 & 5.22984 \\
\hline 13 & 5.32826 & 11.85245 & 2.65514 & 3.05530 & 5.28960 \\
\hline 14 & 2.73041 & 7.05240 & 2.73803 & 3.04382 & 5.34818 \\
\hline 15 & 0.09194 & 2.18782 & 2.82260 & 3.06862 & 5.40864 \\
\hline
\end{tabular}


Table 2. The differences between the corrected and uncorrected flow parameters values, for two flow conditions. Units: SI.

\begin{tabular}{|c|c|c|c|c|c|c|}
\hline & \multicolumn{3}{|c|}{ Dynamic pressure 2941.995 } & \multicolumn{3}{c|}{ Dynamic pressure 5883.990 } \\
\hline & Uncorrected & Corrected & Difference \% & Uncorrected & Corrected & Difference \% \\
\hline Static pressure & 94762.503 & 94671.759 & 0.1 & 94464.859 & 94301.817 & 0.2 \\
\hline Total pressure & 97704.498 & 97613.754 & 0.1 & 100348.849 & 100185.807 & 0.2 \\
\hline Density & 1.107 & 1.106 & 0.1 & 1.103 & 1.101 & 0.2 \\
\hline Velocity & 72.909 & 72.944 & 0.05 & 103.282 & 103.372 & 0.09 \\
\hline Mach & 0.2106 & 0.2107 & 0.05 & 0.2983 & 0.2986 & 0.10 \\
\hline
\end{tabular}

\section{CONCLUSIONS}

An error source was identified in the TA-2 wind tunnel tests, which consists of a nonuniformity of the static pressure. A correction method was suggested, which considers the static pressure indicated by the sensor during the test and the difference between the static pressure at the model position and the upper wall of the tunnel, measured prior to the test. This correction was applied to the parameters static pressure $p$, total pressure $p_{t}$, density $\rho$, velocity $V$ and Mach number $M$, having considered the uncertainty of this correction in the evaluation of the uncertainty of quantities measured and calculated.

The errors, in percentage terms, between the corrected and uncorrected parameters are shown in Table (2). The differences become sharper as the flow velocity increases. For example, when the static pressure correction is not applied, the error in the Mach number is greater $(0.05$ to 0.1 $\%$, when the flow velocity is increased.

Identifying error sources in wind tunnel tests permits the correction of measured quantities. The assessment of uncertainty provides information which helps the aerodynamicist design the experiment in accordance to the requirements set down by the customer. The measurement result depends on the accuracy and uncertainty levels required by the test.

It should be observed that the correction considered in this paper could have been carried out for dynamic pressure and temperature, i. e., in a test situation, the dynamic pressure and temperature at the model position and at the location of the sensor should be related.

\section{REFERENCES}

Anderson, J. D., 1984, Introduction to Flight, New Yrk: MacGraw-Hill Book Company, 3.ed, 616
Benedict, R. P., 1977, Fundamentals of Temperature, Pressure, and Flow Measurements, New York John Wiley. and Sons, 2ed, 517p.

Bureau International des Poids et Mesures, International Electrotechnical Commission, International Federation of Clinical Chemistry, International Organization for Standardization, International Union of Pure and Applied Chemistry, International Union of Pure and Applied Physics, International Organization of Legal Metrology, 1995, Guide to the Expression of Uncertainty in Measurements, 101p.

Instituto Nacional de Metrologia, Normalização e Qualidade Industrial, Rio de Janeiro, 1995, Portaria $N^{\circ} 29$ de 10 de março de 1995, Vocabulário Internacional de Termos Fundamentais e Gerais de Metrologia, 52p. (in Portuguese)

Owen F. K., 2000, Wind Tunnel Flow Quality: Retrospect and Prospect, AIAA 2000$0288,38^{\text {th }}$ Aerospace Sciences Meeting \& Exhibit, 10-13 Jan. 2000, Reno, NV.

Reis M. L. C. C, 2000, Expressão da Incerteza da Medição Associada a um Ensaio Aeronáutico em Túnel de Vento Subsônico, Tese de Doutorado, Universidade Estadual de Campinas, out. de 2000, 103 p. (in Portuguese)

Reis M. L. C. C, Novaski O., Mello O. A. F., Matsuo C., 2000, Incerteza da Medição de um Ensaio em Túnel de Vento Subsônico, Anais do Metrologia2000, 4 - 7 dez. de 2000, São Paulo, pp. 70- 79. (in Portuguese)

p. 